\title{
Accelerated degradation of iopamidol in iron activated persulfate systems: Roles of complexing agents
}

\author{
Huiyu Dong ${ }^{a}$, Zhimin Qiang ${ }^{a, *}$, Jun $\mathrm{Hu}^{\mathrm{a}}$, Carme Sans ${ }^{\mathrm{b}}$ \\ a Key Laboratory of Drinking Water Science and Technology, Research Center for Eco-Environmental Sciences, University of Chinese Academy of Sciences, Chinese Academy of \\ Sciences, Beijing 100085, China \\ ${ }^{\mathrm{b}}$ Department of Chemical Engineering, University of Barcelona, Marti i Franques 1, Barcelona 08028, Spain
}

\section{H I G H L I G H T S}

- GA could activate Fe(III)/PS more effectively than EDTA, EDDS and CA.

- The $k_{\text {obs }}$ of IPM degradation by PS/Fe (III) was increased by 9.2 folds with GA.

- GA promoted Fe(III) reduction and PS decomposition to generate more radicals.

- HO- played a more important role than $\mathrm{SO}_{4}^{--}$in the $\mathrm{PS} / \mathrm{Fe}(\mathrm{III}) / \mathrm{GA}$ system. - $\mathrm{PS} / \mathrm{Fe}(\mathrm{III}) / \mathrm{GA}$ is applicable for removal of organic pollutants from water.

\section{A R T I C L E I N F O}

\section{Article history:}

Received 13 August 2016

Received in revised form 23 January 2017

Accepted 24 January 2017

Available online 27 January 2017

\section{Keywords:}

Gallic acid

Persulfate

Iron ions

Iopamidol
G R A P H I C A L A B S T R A C T

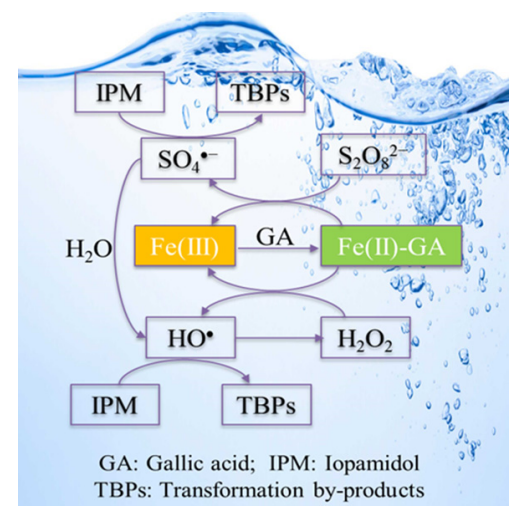

\section{A B S T R A C T}

As an environment-friendly activator, iron ions (Fe(II) and $\mathrm{Fe}(\mathrm{III}))$ have been extensively studied in homogeneous activation of persulfate (PS) to remove organic pollutants from water. However, the slow reduction of $\mathrm{Fe}(\mathrm{III})$ to $\mathrm{Fe}(\mathrm{II})$ and the subsequent low activation efficiency limit the wide applications of $\mathrm{PS} / \mathrm{Fe}(\mathrm{II})$ or PS/Fe(III). In this study, the roles of four complexing agents, including gallic acid (GA), ethylene diamine tetraacetic acid, $(S, S)$-ethylenediamine- $N, N^{\prime}$-disuccinic acid trisodium salt and citric acid in the activation of PS/Fe(III) were comparatively investigated with iopamidol (IPM) used as a model organic pollutant. Results indicate that GA was the most effective with an increase in the observed pseudofirst-order rate constant $\left(k_{\mathrm{obs}}\right)$ by 9.2 folds for IPM degradation by $\mathrm{PS} / \mathrm{Fe}(\mathrm{III})$. Through radical scavenger (ethanol and tert-butanol) tests and electron paramagnetic resonance analysis, $\mathrm{HO}^{-}$and $\mathrm{SO}_{4}^{--}$were identified to be responsible for the accelerated degradation of IPM, and HO played a more important role. Intrinsically, the promoted Fe(III) reduction and PS decomposition accelerated the degradation of IPM. The transformation by-products of IPM in the PS/Fe(III)/GA system were identified and potential degradation pathways were proposed. Besides, the accelerated degradation of other three organic pollutants (methyl orange, congo red, and diclofenac) further demonstrated the applicability of the PS/Fe(III)/GA system to water treatment.

(c) 2017 Elsevier B.V. All rights reserved.

\footnotetext{
* Corresponding author.

E-mail address: qiangz@rcees.ac.cn (Z. Qiang).
} 


\section{Introduction}

Due to their widespread use but incomplete removal during wastewater treatment, the presence of pharmaceuticals in aquatic environments has drawn increasing attention recently. Iodinated X-ray contrast media (ICM) are usually administrated to patients at high doses (up to $200 \mathrm{~g}$ per intravascular administration) $[1,2]$. Because conventional wastewater treatment plants (WWTPs) cannot remove them effectively, ICM compounds have been widely detected in WWTP effluents, surface water and even drinking water [2]. For instance, as a typical ICM compound, iopamidol (IPM) was detected in WWTP effluents $\left(16 \pm 3 \mu \mathrm{g} \mathrm{L}^{-1}\right)$ [3] and drinking water sources (up to $1.9 \mu \mathrm{g} \mathrm{L}^{-1}$ ) [4], which are a few orders of magnitude higher than those of many other pharmaceuticals.

Because of its high iodine-containing nature (around 50\%), IPM not only contributes substantially to the adsorbable fraction of halogenated organics in wastewater, but also acts as a potential iodine source for the formation of iodinated disinfection byproducts [4,5]. Duirk et al. [6] reported that in the presence of IPM, the cytotoxicity and genotoxicity of a source drinking water after chlorination was elevated as assessed with Chinese hamster ovary (CHO) cells. Wendel et al. [7] also observed the chronic cytotoxicity to $\mathrm{CHO}$ cells induced by chlorination of an IPM-containing water. Because of the biological recalcitrance of IPM, physicochemical methods including ozone [8], $\gamma$-irradiation [9] and ultrasound [10] have been applied to remove IPM from water, but the removal efficiency is quite limited. For example, the removal efficiencies of non-ionic and ionic ICM compounds by ozonation were only 35$55 \%$ and $<20 \%$, respectively [8].

Sulfate radical $\left(\mathrm{SO}_{4}^{-}, E_{0}=2.6 \mathrm{~V}\right)$ based advanced oxidation processes (AOPs) have drawn increasing attention for removal of organic pollutants from water. Both persulfate (PS) and peroxymonosulfate can be activated by ultraviolet (UV), heat, base, or transition metal ions (e.g., $\mathrm{Fe}(\mathrm{II}), \mathrm{Co}(\mathrm{II})$ ) to generate $\mathrm{SO}_{4}^{-}$[11]. As a cheap, naturally abundant, and environmental-friendly material, iron ( $\mathrm{Fe}(0), \mathrm{Fe}(\mathrm{II}), \mathrm{Fe}(\mathrm{III})$ ) activation has been preferentially used to generate $\mathrm{SO}_{4}^{--}[12]$. The activation by $\mathrm{Fe}$ (II) requires a relatively lower energy $\left(14.8 \mathrm{kcal} \mathrm{mol}^{-1}\right)$ than the thermal activation (33.5 $\mathrm{kcal} \mathrm{mol}^{-1}$ ), so the $\mathrm{PS} / \mathrm{Fe}(\mathrm{II})$ reaction system has a greater potential for the destruction of organic pollutants $[13,14]$. Fe(II) can readily activate PS to produce $\mathrm{SO}_{4}^{--}$following Eqs. (1) and (2), and then $\mathrm{SO}_{4}^{--}$can trigger a series of chain reactions producing other reactive oxidation species (ROS), particularly hydroxyl radicals (HO*) (Eqs. (3)-(8)).

$$
\begin{aligned}
& \mathrm{Fe}(\mathrm{II})+\mathrm{S}_{2} \mathrm{O}_{8}^{2-} \rightarrow \mathrm{SO}_{4}^{--}+\mathrm{Fe}(\mathrm{III})+\mathrm{SO}_{4}^{2-} \quad k_{1}=30 \mathrm{M}^{-1} \mathrm{~s}^{-1} \\
& \mathrm{Fe}(\mathrm{II})+\mathrm{SO}_{4}^{--} \rightarrow \mathrm{Fe}(\mathrm{III})+\mathrm{SO}_{4}^{2-} \quad k_{2}=4.6 \times 10^{9} \mathrm{M}^{-1} \mathrm{~s}^{-1} \\
& \mathrm{SO}_{4}^{--}+\mathrm{SO}_{4}^{--} \rightarrow 2 \mathrm{SO}_{4}^{2-} \quad k_{3}=4.0 \times 10^{8} \mathrm{M}^{-1} \mathrm{~s}^{-1} \\
& \mathrm{SO}_{4}^{--}+\mathrm{H}_{2} \mathrm{O} \rightarrow \mathrm{SO}_{4}^{2-}+\mathrm{H}^{+}+\mathrm{HO} \quad k_{4}<2.0 \times 10^{7} \mathrm{M}^{-1} \mathrm{~s}^{-1} \\
& \mathrm{SO}_{4}^{--}+\mathrm{H}_{2} \mathrm{O} \rightarrow \mathrm{HSO}_{4}^{-}+\mathrm{HO} \quad k_{5}=2.0 \times 10^{3} \mathrm{M}^{-1} \mathrm{~s}^{-1} \\
& \mathrm{HO}^{-} \mathrm{HO}^{-} \mathrm{H}_{2} \mathrm{O}_{2} \quad k_{6}=5.5 \times 10^{9} \mathrm{M}^{-1} \mathrm{~s}^{-1} \\
& 2 \mathrm{HO}+2 \mathrm{SO}_{4}^{--} \rightarrow 2 \mathrm{HSO}_{4}^{-}+\mathrm{O}_{2} \quad k_{7}=1.0 \times 10^{10} \mathrm{M}^{-1} \mathrm{~s}^{-1} \\
& \mathrm{HO}+\mathrm{S}_{2} \mathrm{O}_{8}^{2-} \rightarrow \mathrm{OH}^{-}+\mathrm{S}_{2} \mathrm{O}_{8}^{-} \quad k_{8}=1.2 \times 10^{7} \mathrm{M}^{-1} \mathrm{~s}^{-1}
\end{aligned}
$$

However, the PS/Fe system has two important limitations: (1) the fast oxidation of $\mathrm{Fe}(\mathrm{II})$ to $\mathrm{Fe}$ (III) by PS rapidly terminates the reaction course; and (2) a high $\mathrm{Fe}(\mathrm{II})$ concentration is needed to fully activate PS, which will strongly competes for $\mathrm{SO}_{4}^{--}$against the target pollutant. Therefore, to maintain the dissolved Fe(II) concentration in the reaction solution, complexing agents such as ethylene diamine tetraacetic acid (EDTA) [15], (S,S)ethylenediamine- $N, N^{\prime}$-disuccinic acid trisodium salt (EDDS) [16], and citric acid (CA) [17] have been tested. However, their promotion on the $\mathrm{Fe}(\mathrm{II}) / \mathrm{Fe}(\mathrm{III})$ cycling was rather limited. Moreover, the non-biodegradability of some complexing agents (e.g. EDTA) in aquatic environments is a stumbling block to their practical applications [18].

In our previous work, we found that gallic acid (GA), a natural complexing agent with environmental benignity, could accelerate the discoloration of methyl orange in Fenton-like (i.e., $\mathrm{H}_{2} \mathrm{O}_{2} / \mathrm{Fe}$ (III)) process through promoting the reduction of $\mathrm{Fe}(\mathrm{III})$ to $\mathrm{Fe}(\mathrm{II})$ [19]. The promoted $\mathrm{Fe}(\mathrm{III}) / \mathrm{Fe}(\mathrm{II})$ cycling by GA may also benefit the PS/Fe system. Meanwhile, the degradation of IPM by PS/Fe (III) has rarely been reported. Based on these considerations, the promotion effect of GA on IPM degradation by PS/Fe(III) was determined in comparison with those of previously reported complexing agents including EDTA, EDDS and CA. Then, the transformation by-products (TBPs) of IPM were identified, and on this basis, the potential degradation pathways were proposed. Besides, the applicability of PS/Fe(III)/GA to water treatment was further verified with other three organic pollutants including methyl orange (MO), congo red (CR) and diclofenac (DCF).

\section{Materials and methods}

\subsection{Chemicals}

All chemicals were at least of analytical grade and used without further purification. Ultra-pure water $(18.2 \mathrm{M} \Omega \cdot \mathrm{cm})$ produced by an Advantage A10 Milli-Q system (Millipore, USA) was used to prepare all reaction solutions. IPM, DCF, 5,5-dimethyl-1-pyrroline $\mathrm{N}$-oxide (DMPO), and four complexing agents (i.e., GA, EDTA, EDDS, and $C A$ ) were purchased from Sigma-Aldrich (Germany). Potassium persulfate, ferrous sulfate heptahydrate, ferric chloride, sodium thiosulfate methyl orange, and CR were all purchased from Sino-Pharm (China). High performance liquid chromatography (HPLC) grade methanol $(\mathrm{MeOH})$, ethanol (EtOH), tert-butanol (TBA), and acetonitrile (ACN) were purchased from Fisher Scientific (Belgium). Formic acid (HPLC grade) was from Dikma Technologies (USA). As a spin-trapping agent for radicals, DMPO and its stock solution were stored at $-18^{\circ} \mathrm{C}$.

\subsection{Experimental procedures}

All experiments were conducted in $250 \mathrm{~mL}$ brown glass reactors in batch mode at ambient temperature $\left(25^{\circ} \mathrm{C}\right)$. A certain volume of PS stock solution was added to the reactor containing the target pollutant, iron ions, and complexing agent with a total volume of $100 \mathrm{~mL}$. Typically, the initial experimental conditions were as follows: $20 \mu \mathrm{M}$ target pollutant, $0.2 \mathrm{mM}$ PS, $10 \mu \mathrm{M}$ Fe(II) or $\mathrm{Fe}(\mathrm{III})$, $10 \mu \mathrm{M}$ complexing agent, and $\mathrm{pH} 7.0$, unless otherwise specified. A relatively high initial concentration of IPM was adopted for kinetic determination and TBP identification. Fe(II) and Fe(III) stock solutions were freshly prepared every day by dissolving an appropriate amount of $\mathrm{FeSO}_{4} \cdot 7 \mathrm{H}_{2} \mathrm{O}$ and $\mathrm{FeCl}_{3} \cdot 6 \mathrm{H}_{2} \mathrm{O}$ in $\mathrm{H}_{2} \mathrm{SO}_{4}$ and $\mathrm{HCl}$ solutions, respectively. The initial $\mathrm{pH}$ of the reaction solution was adjusted by $0.05 \mathrm{M} \mathrm{H}_{2} \mathrm{SO}_{4}$ and $\mathrm{NaOH}$ solutions. Aliquots $(1.0 \mathrm{~mL}$ each) of reaction solution were withdrawn at predetermined time intervals, quenched with $\mathrm{Na}_{2} \mathrm{~S}_{2} \mathrm{O}_{3}$, and analyzed for target species. Each experiment was conducted in triplicate, and the mean values were reported with error bars representing the 95\% confidence interval (i.e., $1.96 \times$ standard deviation (SD)). Additionally, the 
removal of MO, CR, and DCF was tested to assess if their structural difference would impact the effectiveness of the PS/Fe(III)/GA system. To identify the TBPs during IPM degradation by PS/Fe(III)/GA, the reaction was allowed to proceed for $24 \mathrm{~h}$ and then water samples were quenched with $\mathrm{Na}_{2} \mathrm{~S}_{2} \mathrm{O}_{3}$ before analysis.

\subsection{Analytical methods}

IPM and DCF were detected with an Agilent 1200 Series HPLC system equipped with an Atlantis C18 column $(4.6 \times 250 \mathrm{~mm}$, $5.0 \mu \mathrm{m})$ at UV wavelengths of 242 and $274 \mathrm{~nm}$, respectively. The mobile phase was a mixture of methanol/water $(85 / 15, v / v)$ at a flow rate of $1.0 \mathrm{~mL} \mathrm{~min}^{-1}$. The injection volume was $50 \mu \mathrm{L}$, and the column temperature was maintained at $25^{\circ} \mathrm{C}$. The quantification limits of IPM and DCF were 35 and $40 \mu \mathrm{g} \mathrm{L}^{-1}$, respectively. MO and CR were analyzed with a Hach DR 6000 UV-vis spectrophotometer at wavelengths of 466 and $500 \mathrm{~nm}$, respectively. PS and Fe(II) concentrations were determined by an iodometric method [20] and a modified phenanthroline spectrophotometric method [21,22], respectively. Electron paramagnetic resonance (EPR) analysis is detailed in Text S1.

After the complete oxidation of IPM by PS/Fe(III)/GA for $24 \mathrm{~h}$, major TBPs were identified by ultra-performance liquid chromatography-tandem mass spectrometry (UPLC-MS/MS, Agilent 1290 Infinity LC, Agilent 6420 Triple Quad LC/MS detector) coupled with a Waters Acquity $\mathrm{CSH}^{\mathrm{TM}} \mathrm{C} 18$ column $(2.1 \times 100 \mathrm{~mm}, 1.7 \mu \mathrm{m})$. The elution gradients with two mobile phases, including ACN with $0.1 \%$ formic acid $(A)$ and ultrapure water with $0.1 \%$ formic acid $(B)$, were programmed as follows ( $\mathrm{min}, \% \mathrm{~A}):(0,10),(1,10),(5,90),(6$, $90),(6.5,10)$, and $(8,10)$, at a total flow rate of $0.3 \mathrm{~mL} \mathrm{~min}^{-1}$. The column temperature was held constantly at $25^{\circ} \mathrm{C}$ with an injection volume of $10 \mu \mathrm{L}$. The major TBPs were analyzed with both total ion chromatogram (TIC) and selected ion monitoring (SIM) modes.

\subsection{Kinetic model}

The degradation of an organic pollutant in an AOP usually follows the second-order kinetics. Similarly, for IPM degradation in the PS/Fe(II) and PS/Fe(III) systems with or without a complexing agent, the degradation rate can be expressed as follows:

$-\frac{\mathrm{d}[\mathrm{IPM}]}{\mathrm{dt}}=\sum_{i=1}^{n} k_{i}[\mathrm{IPM}]\left[\mathrm{ROS}_{i}\right]$

where the subscript $i$ represents the $i$ th ROS (i.e., radical).

In general, a steady-state concentration can be assumed for the ROS during the reaction course when PS is in large excess of IPM. As a result, Eq. (9) can be simplified to:

$-\frac{\mathrm{d}[\mathrm{IPM}]}{\mathrm{dt}}=k_{\mathrm{obs}}[\mathrm{IPM}]$

where $k_{\text {obs }}$ represents the observed pseudo-first-order rate constant, which can be obtained from the linear regression analysis of time-dependent IPM concentrations.

\section{Results and discussion}

\subsection{IPM degradation by PS/Fe(III) with different complexing agents}

The change of the normalized IPM concentration $\left(C / C_{0}\right)$ with reaction time is illustrated in Fig. 1. An insignificant removal of IPM was observed by both PS and PS/Fe(III). After four complexing agents (GA, EDTA, EDDS and CA, $10 \mu \mathrm{M}$ each) were added individually to the PS/Fe(III) system, the degradation of IPM was accelerated to different extents and GA was the most effective. For example, after reaction for $30 \mathrm{~min}$, about $70 \%$ of IPM was removed

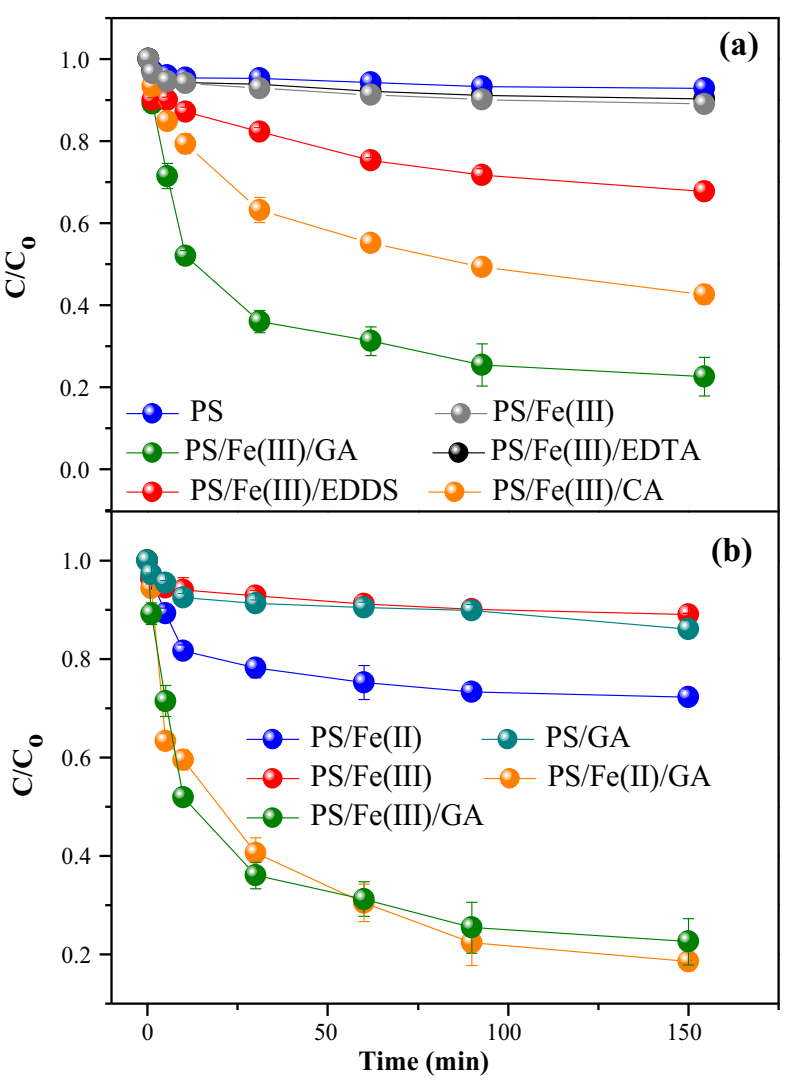

Fig. 1. Effect of various complexing agents on IPM degradation by PS/Fe(III) (a), and effect of GA on IPM degradation by PS/Fe(II) and PS/Fe(III). Experimental conditions: $[\mathrm{IPM}]_{\mathrm{o}}=20 \mu \mathrm{M}, \quad[\mathrm{PS}]_{\mathrm{o}}=0.2 \mathrm{mM}, \quad[\mathrm{Fe}(\mathrm{II}) \text { or } \mathrm{Fe}(\mathrm{III})]_{\mathrm{o}}=10 \mu \mathrm{M}, \quad[$ complexing agent $]_{\mathrm{o}}=10 \mu \mathrm{M}, \mathrm{pH}_{\mathrm{o}}=7.0, \mathrm{~T}=25^{\circ} \mathrm{C}$. Error bars represent the $95 \%$ confidence interval (1.96 SD). PS: persulfate; IPM: iopamidol; GA: gallic acid; EDTA: ethylene diamine tetraacetic acid; EDDS: $(S, S)$-ethylenediamine- $N, N^{\prime}$-disuccinic acid trisodium salt; $C A$ : citric acid.

in the presence of GA, while the promotion effect of EDTA and EDDS was rather limited. As shown in Table 1, the IPM degradation data in the first $30 \mathrm{~min}$ in various PS reaction systems could be well fitted by the pseudo-first-order kinetic model (i.e., Eq. (10)) at an initial molar ratio of $[\mathrm{PS}]_{\mathrm{o}} /[\mathrm{IPM}]_{\mathrm{o}}=10: 1$. Note that the degradation data after 30 min were not included in kinetic analysis because of the tailing effect as a result of side reactions $[23,24]$. The $k_{\text {obs }}$ values of IPM degradation by PS/Fe(III) in the presence of GA, EDTA, EDDS and CA were determined to be $0.048,0.0038,0.0073$ and $0.0025 \mathrm{~min}^{-1}$, respectively (Table 1 ).

It is noted that the $k_{\text {obs }}$ value of PS/Fe(III)/EDTA was relatively lower than that of PS/Fe(III), indicating that EDTA itself could compete for oxidation species in the PS/Fe(III) system. It was proposed previously that EDTA could decrease the $\mathrm{Fe}(\mathrm{III}) / \mathrm{Fe}(\mathrm{II})$ redox potential from 0.77 to $0.21 \mathrm{~V}$, thus subsequently enhancing the

Table 1

Observed pseudo-first-order rate constants $\left(k_{\mathrm{obs}}\right)$ of IPM degradation in various PS reaction systems. Experimental conditions: $[\mathrm{IPM}]_{\mathrm{o}}=20 \mu \mathrm{M},[\mathrm{PS}]_{\mathrm{o}}=0.2 \mathrm{mM},[\mathrm{Fe}(\mathrm{II})$ or $\mathrm{Fe}(\mathrm{III})]_{\mathrm{o}}=10 \mu \mathrm{M}$, [complexing agent $]_{\mathrm{o}}=10 \mu \mathrm{M}, \mathrm{pH}_{\mathrm{o}}=7.0, \mathrm{~T}=25^{\circ} \mathrm{C}, 95 \%$ confidence interval (1.96 SD).

\begin{tabular}{lll}
\hline Reaction system & $k_{\text {obs }}\left(\times 10^{-3} \mathrm{~min}^{-1}\right)$ & $R^{2}$ \\
\hline $\mathrm{PS}$ & $4.0 \pm 0.2$ & 0.97 \\
$\mathrm{PS} / \mathrm{Fe}(\mathrm{II})$ & $6.9 \pm 0.3$ & 0.96 \\
$\mathrm{PS} / \mathrm{Fe}(\mathrm{III})$ & $4.7 \pm 0.1$ & 0.98 \\
$\mathrm{PS} / \mathrm{Fe}(\mathrm{III}) / \mathrm{GA}$ & $48.0 \pm 1.2$ & 0.96 \\
$\mathrm{PS} / \mathrm{Fe}(\mathrm{II}) / \mathrm{GA}$ & $48.6 \pm 1.8$ & 0.95 \\
$\mathrm{PS} / \mathrm{Fe}(\mathrm{III}) / \mathrm{EDTA}$ & $3.8 \pm 0.1$ & 0.94 \\
$\mathrm{PS} / \mathrm{Fe}(\mathrm{III}) / \mathrm{EDDS}$ & $7.3 \pm 0.3$ & 0.96 \\
$\mathrm{PS} / \mathrm{Fe}(\mathrm{III}) / \mathrm{CA}$ & $25.4 \pm 0.7$ & 0.97 \\
\hline
\end{tabular}


thermodynamic reactivity of the Fenton process [25,26]. However, GA and EDTA could have different roles in promoting the $\mathrm{Fe}(\mathrm{III}) / \mathrm{Fe}$ (II) cycling. GA could form complexes of high stability with iron ions via two adjacent - $\mathrm{OH}$ groups, where the complexation continued from $\mathrm{pH} 3.0$ to 9.0 [27]. Moreover, GA itself as a reducing agent could directly convert Fe(III) to $\mathrm{Fe}(\mathrm{II})$, thus accelerating the $\mathrm{Fe}(\mathrm{III}) /$ $\mathrm{Fe}(\mathrm{II})$ cycling more effectively than other three complexing agents examined.

Fig. 1b compares the degradation kinetics of IPM by PS/Fe(III) and $\mathrm{PS} / \mathrm{Fe}(\mathrm{II})$ in the presence or absence of GA. The addition of GA could promote the removal of IPM by PS/Fe(II) as well. Due to a lack of reducing agent, a high initial dose of $\mathrm{Fe}(\mathrm{II})$ is generally adopted to activate PS in the PS/Fe(II) system, which can also compete for oxidation species against the target pollutant. After the addition of GA, the $k_{\mathrm{obs}}$ value of IPM degradation increased by about 6 folds as compared to that in the PS/Fe(II) system. In addition, the similar $k_{\text {obs }}$ values in the PS/Fe(II)/GA and PS/Fe(III)/GA systems demonstrated that GA could timely facilitate the reduction of $\mathrm{Fe}(\mathrm{III})$ to $\mathrm{Fe}(\mathrm{II})$ in both systems. After reaction for $150 \mathrm{~min}$, the removal of IPM by PS/GA was less than $15 \%$, similar to that by $\mathrm{PS} / \mathrm{Fe}(\mathrm{III})$. By contrast, the removal of IPM by PS/Fe(III)/GA reached nearly $80 \%$, implying that GA did not directly activate PS in this reaction system. Moreover, with the addition of GA, a low Fe(III)/ PS (or Fe(II)/PS) molar ratio of 0.05 was able to remove most of IPM, which is much lower than other complexing agents (e.g., 0.4 for ascorbic acid [28] and 0.5 for oxalic acid [29]).

\subsection{Effect of initial reactant dose}

\subsubsection{Effect of initial $\mathrm{Fe}(\mathrm{III}) / \mathrm{PS}$ molar ratio}

In the PS/Fe(III)/GA system, the effects of the initial concentrations of Fe(III), PS, and GA on IPM degradation were tested. Fig. 2a shows that the removal of IPM was increased from $45 \%$ to $64 \%$ at the reaction time of $30 \mathrm{~min}$ when the initial $\mathrm{Fe}(\mathrm{III}) / \mathrm{PS}$ molar ratio was increased from 0.025 to 0.05 . However, the removal of IPM was only slightly improved when the initial $\mathrm{Fe}(\mathrm{III}) / \mathrm{PS}$ molar ratio was further increased up to 2.5. An excessive dose of Fe(III) could act as a scavenger of oxidative radicals in the PS/Fe(III)/GA system, as described in Eq. (11) [30]:

$\mathrm{Fe}(\mathrm{III})+\mathrm{HO}_{2}^{--} / \mathrm{O}_{2}^{--} \rightarrow \mathrm{Fe}(\mathrm{II})+\mathrm{O}_{2}+\mathrm{H}^{+}$

\subsubsection{Effect of initial PS concentration}

The effect of initial PS concentration on IPM degradation was investigated with $100,200,400$, and $1000 \mu \mathrm{M}$ at fixed $\mathrm{Fe}(\mathrm{III})$ and GA concentrations (i.e., both $10 \mu \mathrm{M}$ ). Fig. $2 \mathrm{~b}$ shows that the removal of IPM at the reaction time of $30 \mathrm{~min}$ increased from $38 \%$ to $62 \%$ when the PS concentration rose from 100 to $200 \mu \mathrm{M}$; a further increase in the initial PS concentration resulted in higher IPM removal rates before $10 \mathrm{~min}$, but the final removal efficiency of IPM was only slightly improved at $30 \mathrm{~min}$. When applied in excess, PS could not only compete for HO- (Eq. (8)), but also facilitate the abundant $\mathrm{SO}_{4}^{--}$to merge into the useless $\mathrm{SO}_{4}^{2-}$ ions (Eq. (3)), thus causing a decrease in the IPM removal efficiency.

\subsubsection{Effect of initial $\mathrm{GA} / \mathrm{Fe}(\mathrm{III})$ molar ratio}

As shown in Fig. 2c, the removal of IPM was first enhanced and then inhibited when the initial GA/Fe(III) molar ratio increased from 0 to 10, at a fixed Fe(III) dosage of $10 \mu \mathrm{M}$. Addition of GA with an appropriate amount could obviously enhance the degradation of IPM because it could accelerate the $\mathrm{Fe}(\mathrm{III}) / \mathrm{Fe}(\mathrm{II})$ cycling through forming complexes with iron ions. The $\mathrm{Fe}(\mathrm{III}) / \mathrm{Fe}(\mathrm{II})-\mathrm{GA}$ complexes (e.g., $[\mathrm{Fe}(\mathrm{III})(\mathrm{GA})]^{+},\left[\mathrm{Fe}(\mathrm{III})(\mathrm{GA})_{2}\right]^{-},[\mathrm{Fe}(\mathrm{II})(\mathrm{GA})]$, and $\left[\mathrm{Fe}(\mathrm{II})(\mathrm{GA})_{2}\right]^{2-}$ ) are more stable than $\mathrm{Fe}(\mathrm{II})$ and $\mathrm{Fe}(\mathrm{III})$ in aqueous phase (Eqs. (12) and (13)). GA presented a more rapid electron transfer rate in

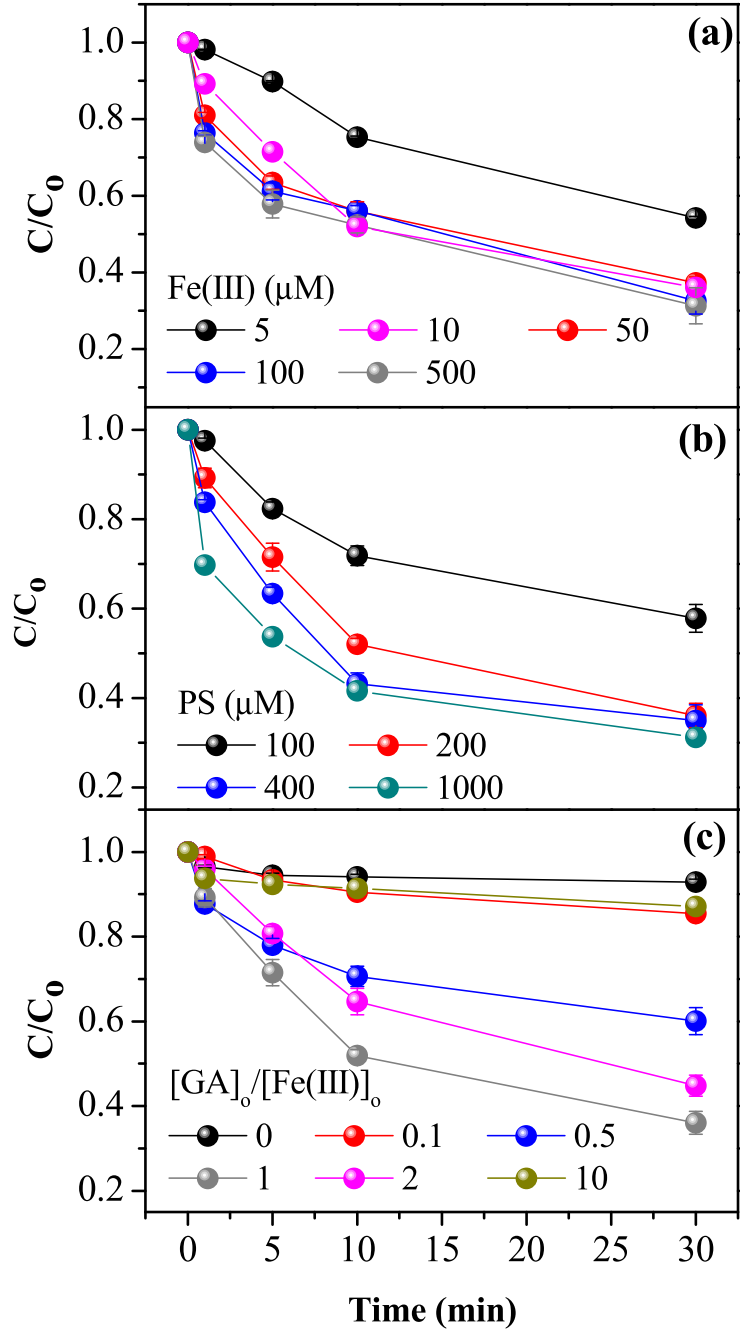

Fig. 2. Effects of initial $\mathrm{Fe}(\mathrm{III})$ concentration (a), PS concentration (b), and $[\mathrm{GA}]_{\mathrm{o}} /[\mathrm{Fe}(\mathrm{III})]_{\mathrm{o}}$ molar ratio (c) on IPM degradation by PS/Fe(III)/GA. Experimental conditions: $[\mathrm{IPM}]_{\mathrm{o}}=20 \mu \mathrm{M}, \mathrm{pH}_{\mathrm{o}}=7.0, \mathrm{~T}=25^{\circ} \mathrm{C}$; (a) $[\mathrm{PS}]_{\mathrm{o}}=0.2 \mathrm{mM},[\mathrm{GA}]_{\mathrm{o}}=10 \mu \mathrm{M}$; (b) $[\mathrm{Fe}(\mathrm{III})]_{\mathrm{o}}=10 \mu \mathrm{M},[\mathrm{GA}]_{\mathrm{o}}=10 \mu \mathrm{M}$; (c) $[\mathrm{PS}]_{\mathrm{o}}=0.2 \mathrm{mM},[\mathrm{Fe}(\mathrm{III})]_{\mathrm{o}}=10 \mu \mathrm{M}$. Error bars represent the $95 \%$ confidence interval (1.96 SD).

catalyzing Fenton's reaction than sulfuric acid [19]. Consequently, through complexing with and also reduction of $\mathrm{Fe}(\mathrm{III}), \mathrm{GA}$ could effectively improve the activation of PS by Fe(II). However, when the $\mathrm{GA} / \mathrm{Fe}(\mathrm{III})$ molar ratio increased to above 1.0 , the removal of IPM was considerably inhibited. In particular, at the highest molar ratio tested (i.e., $\mathrm{GA} / \mathrm{Fe}(\mathrm{III})=10$ ), the improvement in IPM removal was almost negligible. An excessive GA was likely to shield Fe(II) and $\mathrm{Fe}(\mathrm{III})$ ions and inhibit their contact with PS to some extent. Meanwhile, GA itself may act as a radical scavenger when dosed in excess. Therefore, the optimal GA/Fe(III) molar ratio was 1.0, which corresponded to a considerably low GA/PS molar ratio of 0.05 and demonstrated the high efficiency of GA in activating the $\mathrm{PS} / \mathrm{Fe}(\mathrm{III})$ system for organic pollutant removal.

$\mathrm{Fe}(\mathrm{II})+\mathrm{GA}^{2-} \rightarrow[\mathrm{Fe}(\mathrm{III})(\mathrm{GA})]^{+}$
$[\mathrm{Fe}(\mathrm{III})(\mathrm{GA})]^{+}+\mathrm{GA}^{2-} \rightarrow\left[\mathrm{Fe}(\mathrm{III})(\mathrm{GA})_{2}\right]^{-}$

\subsection{Effect of initial $p H$}

In Fenton and Fenton-like systems, a narrow pH range of 2.04.0 is usually necessary for the effective activation of oxidant(s) by $\mathrm{Fe}(\mathrm{II})$ and/or $\mathrm{Fe}(\mathrm{III})$. Moreover, as Fe(II) is readily oxidized to 


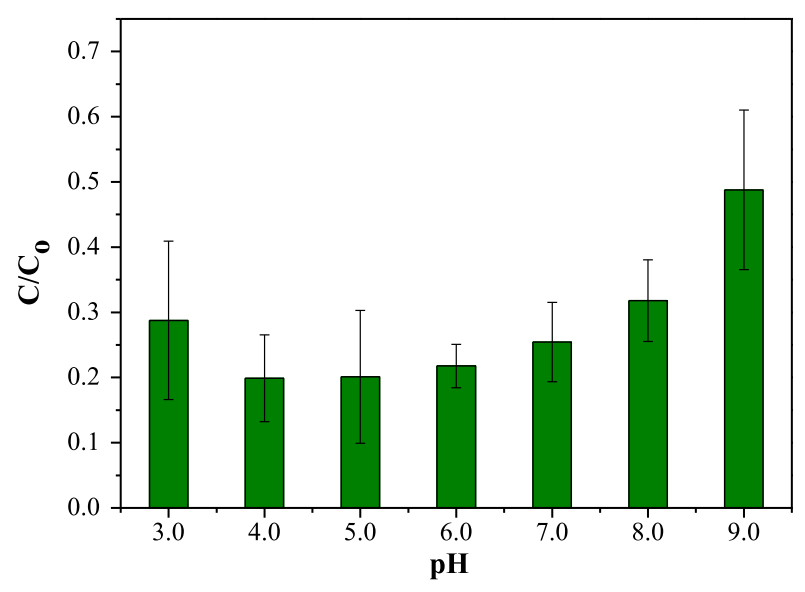

Fig. 3. Effect of initial $\mathrm{pH}$ on IPM degradation by $\mathrm{PS} / \mathrm{Fe}(\mathrm{III}) / \mathrm{GA}$. Experimental conditions: $[\mathrm{IPM}]_{\mathrm{o}}=20 \mu \mathrm{M}, \quad[\mathrm{PS}]_{\mathrm{o}}=0.2 \mathrm{mM}, \quad[\mathrm{Fe}(\mathrm{III})]_{\mathrm{o}}=10 \mu \mathrm{M}, \quad[\mathrm{GA}]_{\mathrm{o}}=10 \mu \mathrm{M}$ $\mathrm{T}=25^{\circ} \mathrm{C}$, reaction time $=30 \mathrm{~min}$. Error bars represent the $95 \%$ confidence interval (1.96 SD).

$\mathrm{Fe}(\mathrm{III})$ in the oxidation system, the precipitation of $\mathrm{Fe}(\mathrm{III})$ is inevitable at $\mathrm{pH}>4.0$, which will retard the removal of target pollutants [31,32]. Fig. 3 shows that PS/Fe(III)/GA could achieve a fairly high removal efficiency of IPM (ca. 70-80\%) over the pH range of 3.08.0. This result demonstrates that the addition of GA could well maintain the water solubility of iron ions and thus broaden the reaction $\mathrm{pH}$ range. However, when the initial $\mathrm{pH}$ further increased to 9.0, the complexing and reducing abilities of GA weakened and $\mathrm{Fe}(\mathrm{II})$ and $\mathrm{Fe}(\mathrm{III})$ precipitated as corresponding oxyhydroxides, which subsequently decreased the IPM removal efficiency to $52 \%$. Han et al. [27] also reported that under an alkaline condition ( $\mathrm{pH}$ 9.0 ), the availability of Fe(II) was largely reduced because it tended to form mixed complexes with the abundant $\mathrm{OH}^{-}$. In brief, in the typical $\mathrm{pH}$ range (6.0-8.0) of surface and ground waters, the addition of GA could significantly enhance the removal of IPM in the PS/ $\mathrm{Fe}(\mathrm{III})$ system.

\subsection{Roles of GA in the PS/Fe(III)/GA system}

Based on the results aforementioned, it was hypothesized that the addition of GA could accelerate IPM degradation by PS/Fe(III) through facilitating the reduction of $\mathrm{Fe}(\mathrm{III})$ to $\mathrm{Fe}(\mathrm{II})$. To verify the roles of GA, the concentration profiles of $\mathrm{Fe}(\mathrm{II})$ and PS in the PS/Fe

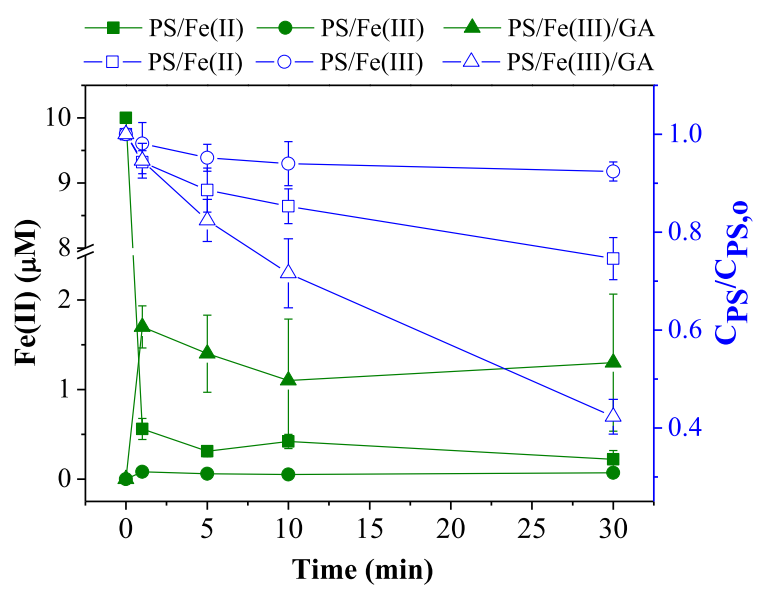

Fig. 4. Changes of $\mathrm{Fe}(\mathrm{II})$ and PS concentrations during IPM degradation by $\mathrm{PS} / \mathrm{Fe}(\mathrm{II})$, $\mathrm{PS} / \mathrm{Fe}(\mathrm{III})$ and $\mathrm{PS} / \mathrm{Fe}(\mathrm{III}) / \mathrm{GA}$. Experimental conditions: $[\mathrm{IPM}]_{0}=20 \mu \mathrm{M}, \quad[\mathrm{PS}]_{0}=$ $0.2 \mathrm{mM},[\mathrm{Fe}(\mathrm{II}) \text { or } \mathrm{Fe}(\mathrm{III})]_{\mathrm{o}}=10 \mu \mathrm{M},[\mathrm{GA}]_{\mathrm{o}}=10 \mu \mathrm{M}, \mathrm{pH}_{\mathrm{o}}=7.0, \mathrm{~T}=25^{\circ} \mathrm{C}$. Error bars represent the $95 \%$ confidence interval $(1.96 \mathrm{SD})$.

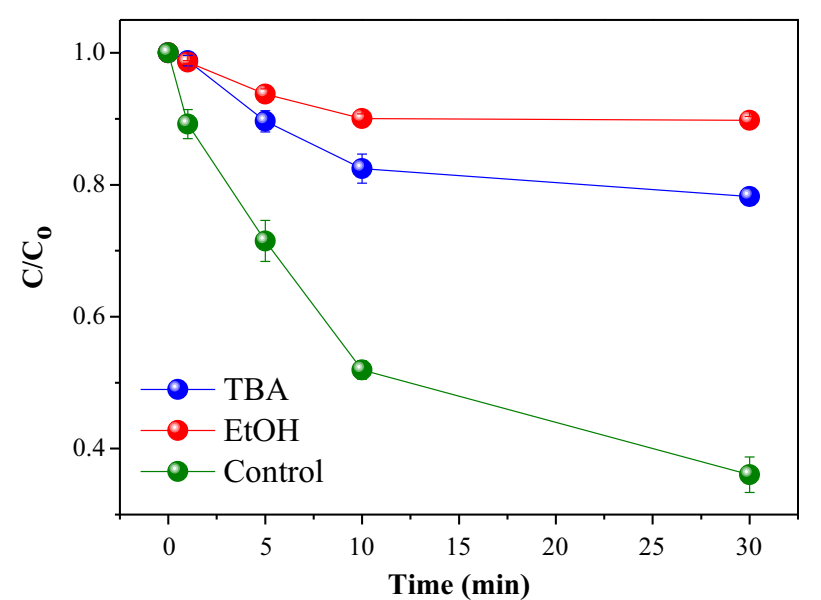

Fig. 5. Effect of radical scavengers (EtOH and TBA) on IPM degradation by $\mathrm{PS} / \mathrm{Fe}(\mathrm{III}) /$ GA. Experimental conditions: $[\mathrm{IPM}]_{\mathrm{o}}=20 \mu \mathrm{M},[\mathrm{PS}]_{\mathrm{o}}=0.2 \mathrm{mM},[\mathrm{Fe}(\mathrm{III})]_{\mathrm{o}}=10 \mu \mathrm{M}$, $[\mathrm{GA}]_{\mathrm{o}}=10 \mu \mathrm{M},[\mathrm{EtOH} \text { or TBA }]_{\mathrm{o}}=200 \mathrm{mM}, \mathrm{pH}_{\mathrm{o}}=7.0, \mathrm{~T}=25^{\circ} \mathrm{C}$. Error bars represent the $95 \%$ confidence interval (1.96 SD). EtOH: ethanol; TBA: tert-butanol.

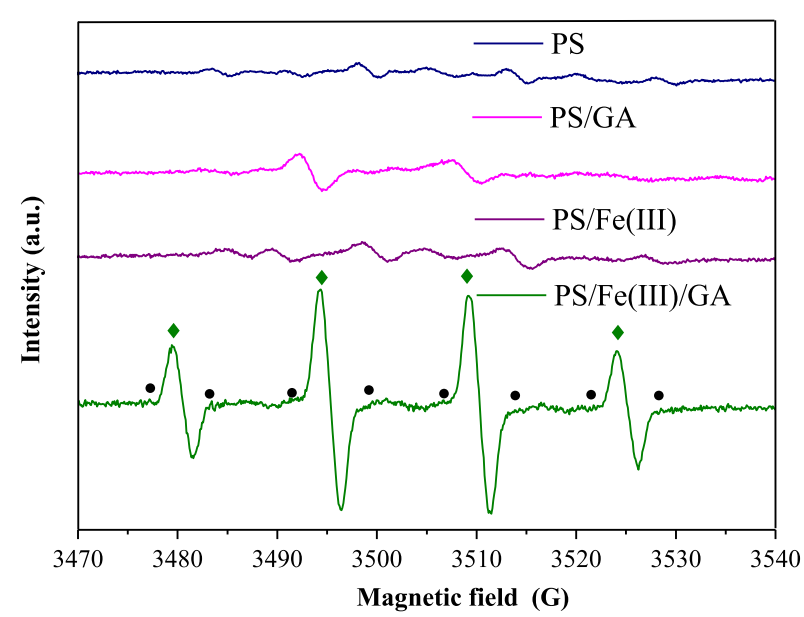

Fig. 6. EPR spectra of DMPO-OH and $\mathrm{DMPO}^{-\mathrm{SO}_{4}}$ adducts in $\mathrm{PS}, \mathrm{PS} / \mathrm{GA}, \mathrm{PS} / \mathrm{Fe}(\mathrm{III})$ and $\mathrm{PS} / \mathrm{Fe}(\mathrm{III}) / \mathrm{GA}$. Experimental conditions: $[\mathrm{IPM}]_{\mathrm{o}}=20 \mu \mathrm{M}, \quad[\mathrm{PS}]_{\mathrm{o}}=0.2 \mathrm{mM}, \quad[\mathrm{Fe}$ (III) $]_{\mathrm{o}}=10 \mu \mathrm{M},[\mathrm{GA}]_{\mathrm{o}}=10 \mu \mathrm{M},[\mathrm{DMPO}]_{\mathrm{o}}=100 \mathrm{mM}, \mathrm{pH}_{\mathrm{o}}=7.0, \mathrm{~T}=25^{\circ} \mathrm{C}$. Symbols: - DMPO-SO 4 adduct, $\bullet$ DMPO-OH adduct.

(II), PS/Fe(III) and PS/Fe(III)/GA systems were compared. As shown in Fig. 4, about $95 \%$ of $\mathrm{Fe}(\mathrm{II})$ was promptly oxidized to $\mathrm{Fe}(\mathrm{III})$ within $1 \mathrm{~min}$ in the PS/Fe(II) system, which was due to the fast oxidation of $\mathrm{Fe}(\mathrm{II})$ by PS and the very slow reduction of Fe(III) to Fe(II). In the PS/Fe (III)/GA system, the concentration of Fe(II) rapidly increased to $1.75 \mu \mathrm{M}$ after $1 \mathrm{~min}$ and then approximately maintained in dynamic equilibrium until the end of the reaction, indicating that GA could effectively facilitate the $\mathrm{Fe}(\mathrm{III}) / \mathrm{Fe}(\mathrm{II})$ cycling. By contrast, very low $\mathrm{Fe}(\mathrm{II})$ concentrations were detected over the whole reaction period in the PS/Fe(III) system in the absence of GA.

Accordingly, a quick consumption of PS was observed in the PS/ $\mathrm{Fe}(\mathrm{III}) / \mathrm{GA}$ system, as a result of the effective recovery of $\mathrm{Fe}(\mathrm{II})$. At the reaction time of $30 \mathrm{~min}, 58 \%$ of PS was consumed in the PS/ $\mathrm{Fe}(\mathrm{III}) / \mathrm{GA}$ system, as compared to a $25 \%$ consumption in the PS/ $\mathrm{Fe}(\mathrm{II})$ system. This result indicates again that the addition of GA could accelerate the recovery of $\mathrm{Fe}(\mathrm{II})$ and the consumption of PS, and thus enhancing the removal of IPM.

\subsection{Identification of ROS}

Two radical scavengers (TBA or EtOH) were individually added to identify whether $\mathrm{HO}^{-}$and/or $\mathrm{SO}_{4}^{--}$were generated in the $\mathrm{PS} / \mathrm{Fe}$ 


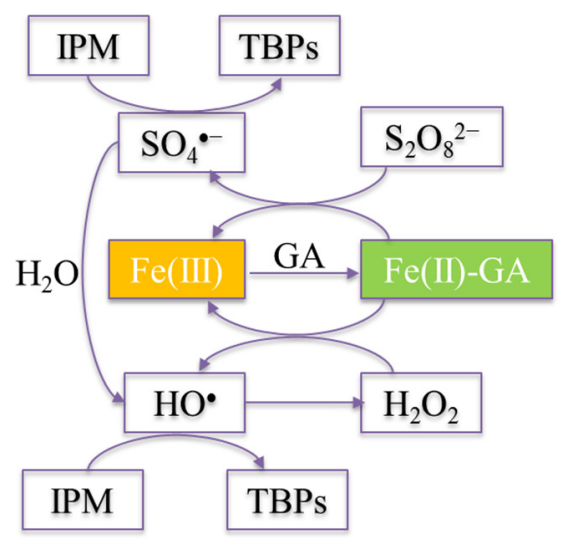

Scheme 1. Proposed mechanism for accelerated IPM degradation by PS/Fe(III)/GA.
(III)/GA system [33]. The reaction rate constant of EtOH with HO' is approximately $(2.0-3.0) \times 10^{9} \mathrm{M}^{-1} \mathrm{~s}^{-1}$, which is about 50 times that with $\mathrm{SO}_{4}^{--}$(i.e., $(4.0-5.5) \times 10^{7} \mathrm{M}^{-1} \mathrm{~s}^{-1}$ ). The reaction rate constant of TBA with HO' is approximately $(5.0-6.0) \times 10^{8} \mathrm{M}^{-1} \mathrm{~s}^{-1}$, which is nearly 1000 times that with $\mathrm{SO}_{4}^{-}$(i.e., $(7.0-8.0) \times$ $10^{5} \mathrm{M}^{-1} \mathrm{~s}^{-1}$ ). Thus, the role of HO in the PS/Fe(III)/GA system could be identified by adding an excessive TBA, and the role of $\mathrm{SO}_{4}^{--}$could also be evaluated by comparing the difference between the removal efficiencies of IPM after adding an excessive TBA or EtOH. Fig. 5 shows that without any radical scavenger, 64\% of IPM was degraded at $30 \mathrm{~min}$. Whereas, the addition of $200 \mathrm{mM}$ TBA or EtOH resulted in only $22 \%$ and $10 \%$ IPM degradation at $30 \mathrm{~min}$, respectively, indicating that the accelerated IPM degradation by $\mathrm{PS} / \mathrm{Fe}(\mathrm{III}) / \mathrm{GA}$ was attributed to the combined effects of $\mathrm{SO}_{4}^{--}$and $\mathrm{HO} . \mathrm{SO}_{4}^{--}$was firstly thought as the primary ROS during the oxidation of PS; however, the contribution of $\mathrm{SO}_{4}^{--}$was not remarkable,

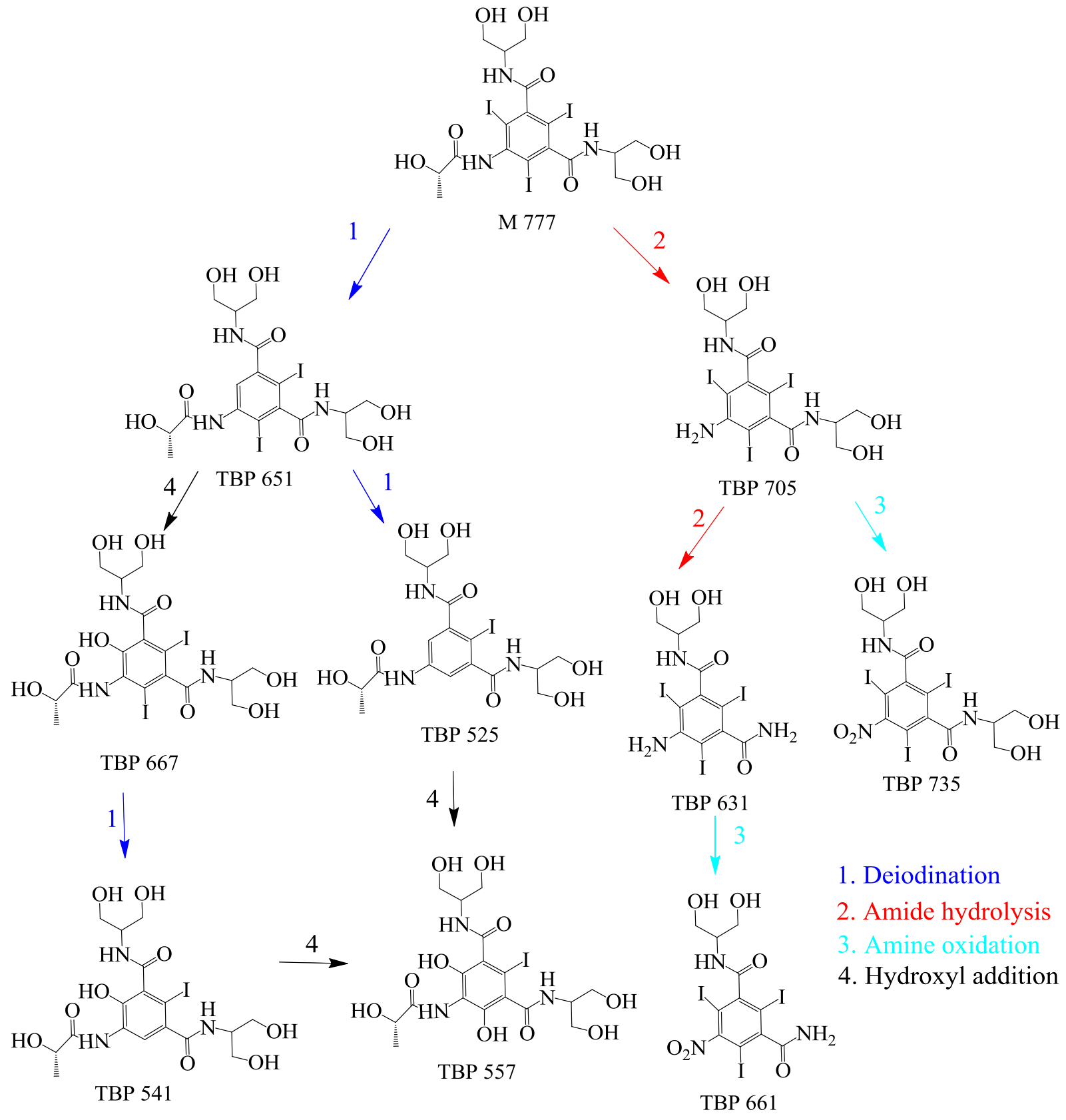

Fig. 7. Proposed pathways of IPM degradation by PS/Fe(III)/GA. 


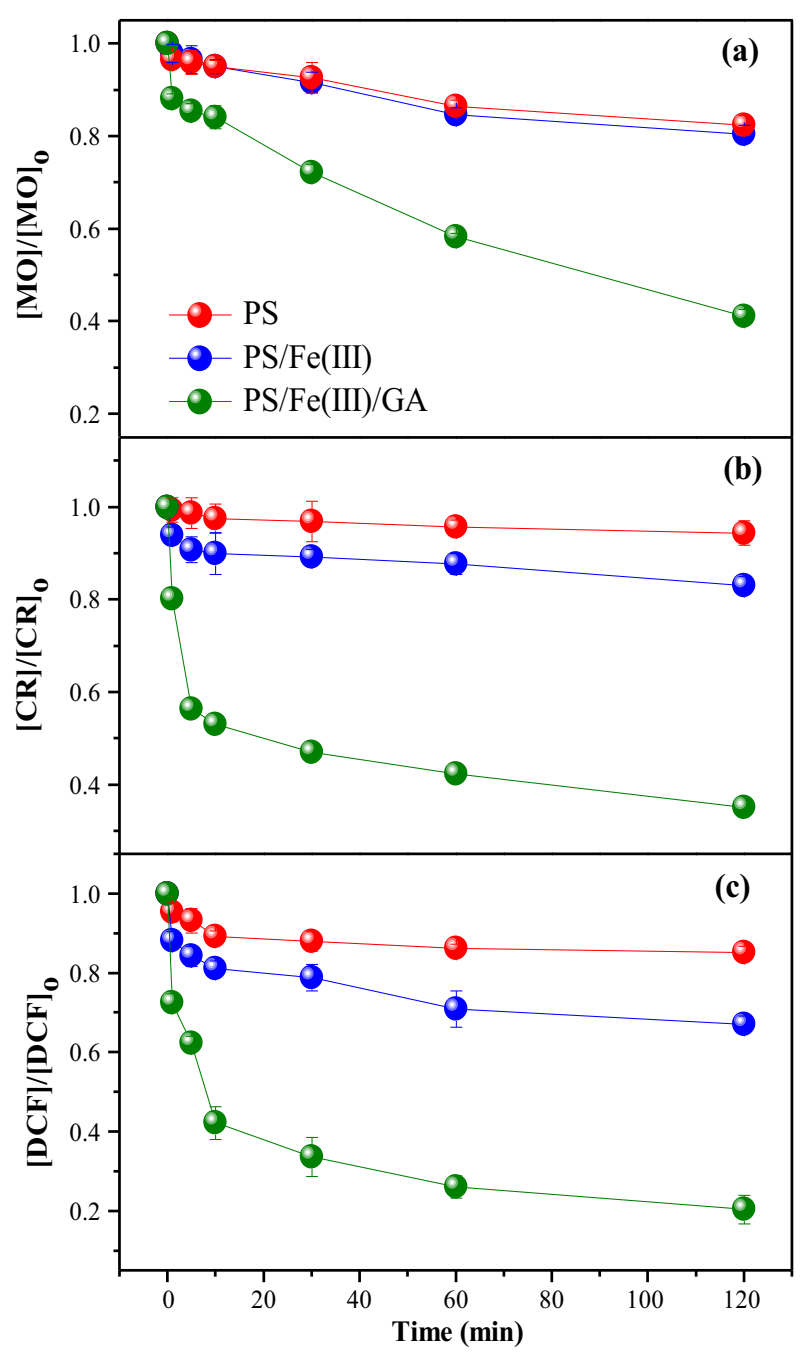

Fig. 8. Degradation of MO (a), CR (b), and DCF (c) by PS/Fe(III)/GA. Experimental conditions: $[\mathrm{MO}, \mathrm{CR} \text {, or } \mathrm{DCF}]_{\mathrm{o}}=20 \mu \mathrm{M}, \quad[\mathrm{PS}]_{\mathrm{o}}=0.2 \mathrm{mM}, \quad[\mathrm{Fe}(\mathrm{III})]_{\mathrm{o}}=10 \mu \mathrm{M}$, $[\mathrm{GA}]_{\mathrm{o}}=10 \mu \mathrm{M}, \mathrm{pH}_{\mathrm{o}}=7.0, \mathrm{~T}=25^{\circ} \mathrm{C}$. Error bars represent the $95 \%$ confidence interval (1.96 SD). MO: methyl orange; CR: congo red; DCF: diclofenac.

probably due to the reaction between $\mathrm{SO}_{4}^{--}$and $\mathrm{H}_{2} \mathrm{O}$ (Eq. (4)). The formation of $\mathrm{HO}$ is highly $\mathrm{pH}$-dependent, which is facilitated under acidic conditions. Zhou et al. (2013) [34] found that the contribution of HO was more significant in acidic conditions than in alkaline conditions in the PS system. In the PS/Fe(III)/GA system, the addition of GA promoted the formation of $\mathrm{SO}_{4}^{--}$and $\mathrm{HO}^{-}$in sequence, which gave $\mathrm{HO}^{-}$a more important role in oxidizing IPM.

EPR spectra were recorded with DMPO as a spin-trapping agent to examine the ROS generated in the PS, PS/GA, PS/Fe(III) and PS/Fe (III)/GA systems. The EPR spectrum of PS/Fe(III)/GA clearly showed four characteristic peaks of DMPO-OH adduct (with an intensity ratio of $1: 2: 2: 1$ and hyperfine splitting constants of $\mathrm{a}_{\mathrm{N}}=\mathrm{a}_{\mathrm{H}}=$ $14.9 \mathrm{G})$ [35], and the characteristic peaks of $\mathrm{DMPO}^{-\mathrm{SO}_{4}}$ adduct (with hyperfine splitting constants of $\mathrm{a}_{\mathrm{H}}=9.6 \mathrm{G}, \mathrm{a}_{\mathrm{H}}=1.48 \mathrm{G}$, and $a_{H}=0.78 G$ ) [36]. However, these characteristic peaks were hardly discernable in other three systems (Fig. 6). In addition, the DMPO$\mathrm{SO}_{4}$ adduct showed much weaker signals than the DMPO-OH adduct, most probably due to the rapid transformation of $\mathrm{SO}_{4}^{--}$to $\mathrm{HO}$ in the presence of GA as aforementioned.

Based on the identified ROS through radical scavenger experiments, the mechanism for the accelerated IPM degradation by $\mathrm{PS} / \mathrm{Fe}(\mathrm{III}) / \mathrm{GA}$ is proposed in Scheme 1. The addition of GA to $\mathrm{PS} / \mathrm{Fe}(\mathrm{III})$ induced the formation of $[\mathrm{Fe}(\mathrm{III})(\mathrm{GA})]^{+},\left[\mathrm{Fe}(\mathrm{III})(\mathrm{GA})_{2}\right]^{-}$ and $\mathrm{Fe}(\mathrm{II})$ (Eqs. (12)-(14)). Thus, the total dissolved $\mathrm{Fe}(\mathrm{II})$ concentration increased, which could effectively convert PS to $\mathrm{SO}_{4}^{--}$. In addition, the formation of $\mathrm{HO}$ could be promoted through the Fenton reaction (Eq. (16)) and the oxidation of $\mathrm{H}_{2} \mathrm{O}$ by $\mathrm{SO}_{4}^{--}$ (Eq. (4)) as well. Both $\mathrm{HO}^{-}$and $\mathrm{SO}_{4}^{--}$could then oxidize IPM, resulting in the formation of $\mathrm{SO}_{4}^{2-}$ and TBPs.

$$
\begin{aligned}
& 4 \mathrm{Fe}(\mathrm{III})+\mathrm{GA} \rightarrow 4 \mathrm{Fe}(\mathrm{II})+\text { quinones }+4 \mathrm{H}^{+} \\
& {[\mathrm{Fe}(\mathrm{II})-\mathrm{GA}]+\mathrm{S}_{2} \mathrm{O}_{8}^{2-} \rightarrow \mathrm{Fe}(\mathrm{III})+\mathrm{SO}_{4}^{2-}+\mathrm{SO}_{4}^{--}} \\
& \mathrm{H}_{2} \mathrm{O}_{2}+\mathrm{Fe}(\mathrm{II}) \rightarrow \mathrm{OH}^{-}+\mathrm{Fe}(\mathrm{III})+\mathrm{HO}
\end{aligned}
$$

\subsection{Identification of major TBPs}

After the complete oxidation of IPM by PS/Fe(III)/GA for $24 \mathrm{~h}$, the reaction solution was analyzed by UPLC-MS/MS to identify the major TBPs. Table S1 summarizes the major TBPs of IPM and their proposed molecular formulae. The TIC and SIM chromatograms are shown in Figs. S1 and S2, respectively. As shown in Fig. 7, four main reaction steps leading to IPM degradation were proposed. TBP 651 originated from the cleavage of one iodine atom and hydrogen substitution in sequence. The stepwise deiodination of IPM was also followed by hydroxyl addition at the lost iodine sites on the aromatic ring (TBP 667 and TBP 557). Similar deiodination reactions have been reported previously during the UV photolysis of IPM [37]. An iodinated group was more prone to be cleaved than a chlorinated analogue during AOPs $[9,38]$. Apart from the deiodination and hydroxyl addition reactions, other reactions responsible for IPM degradation in the PS/Fe(III)/GA system could include amide hydrolysis (producing TBP 705 and TBP 631) and the subsequent amine oxidation (producing TBP 735 and TBP 661 ) on the side chains. Hydrogen abstraction from IPM, which usually occurs slowly for electron-rich compounds [4], was not observed in this study. This is reasonable because the accelerated formation of $\mathrm{HO}^{-}$and $\mathrm{SO}_{4}^{--}$rendered deiodination, hydroxyl addition, amide hydrolysis, and amine oxidation the main reaction steps for the degradation of IPM in the PS/Fe(III)/GA system.

\subsection{Environmental implications}

The removal of other three organic pollutants (i.e., MO, CR and $\mathrm{DCF}$ ) in the PS, PS/Fe(III) and PS/Fe(III)/GA systems was also examined to further evaluate the applicability of PS/GA/Fe(III). Fig. 8 shows that PS/Fe(III)/GA could degrade all the three pollutants more effectively than PS and PS/Fe(III). After reaction for $60 \mathrm{~min}$, MO, CR and DCF were removed by $42 \%, 58 \%$ and $74 \%$ in the $\mathrm{PS} / \mathrm{Fe}$ (III)/GA system, respectively, at an initial PS/Fe(III)/GA/pollutant molar ratio of $20: 1: 1: 2$. By contrast, the corresponding removal efficiencies in the PS/Fe(III) system were only $14 \%, 13 \%$ and $29 \%$, respectively.

From all the tested organic pollutants, the PS/GA/Fe(III) system exhibited stable acceleration on their degradation. Nowadays, PS is being increasingly used for in-situ chemical oxidation (ISCO) of organic pollutants in groundwater [39]. Since iron ubiquitously exists in soils and groundwater at different levels, the promotion of GA on the iron cycling found in this study denotes that the PS-based ISCO process can be remarkably enhanced by external addition of GA.

\section{Conclusions}

This study investigated the promotion effect of GA on IPM degradation by $\mathrm{PS} / \mathrm{Fe}(\mathrm{III})$. Based on the experimental results, the following conclusions are drawn: 
- GA outperformed EDTA, EDDS and CA for the activation of PS/Fe (III).

- The $k_{\mathrm{obs}}$ value of IPM degradation by PS/Fe(III)/GA was increased significantly to $0.048 \mathrm{~min}^{-1}$, which is about 10.2 and 7.0 times those by PS/Fe(III) and PS/Fe(II), respectively.

- GA promoted Fe(III) reduction and PS decomposition to generate more radicals, thus accelerating IPM degradation by PS/Fe (III).

- $\mathrm{HO}$ - played a more important role than $\mathrm{SO}_{4}^{--}$in IPM degradation by $\mathrm{PS} / \mathrm{Fe}(\mathrm{III}) / \mathrm{GA}$.

\section{Acknowledgments}

This work was financially supported by the National Natural Science Foundation of China (51408590, 51290281, 51525806), Chinese Academy of Sciences (QYZDY-SSW-DQC004), and the People Program (Marie Curie Actions) of the European Union's Seventh Program FP7/2007-2013 under a REA grant (Agreement No. 318926).

\section{Appendix A. Supplementary data}

Supplementary data associated with this article can be found, in the online version, at http://dx.doi.org/10.1016/j.cej.2017.01.099.

\section{References}

[1] C. Christiansen, X-ray contrast media-an overview, Toxicology 209 (2005) 185-187.

[2] S. Perez, D. Barcelo, Fate and occurrence of X-ray contrast media in the environment, Anal. Bioanal. Chem. 387 (2007) 1235-1246.

[3] J.L. Kormos, M. Schulz, T.A. Ternes, Occurrence of iodinated X-ray contrast media and their biotransformation products in the urban water cycle, Environ. Sci. Technol. 45 (2011) 8723-8732.

[4] D. Simazaki, R. Kubota, T. Suzuki, M. Akiba, T. Nishimura, S. Kunikane Occurrence of selected pharmaceuticals at drinking water purification plants in Japan and implications for human health, Water Res. 76 (2015) 187-200.

[5] C. Zhao, L.E. Arroyo-Mora, A.P. DeCaprio, V.K. Sharma, D.D. Dionysiou, K.E. O'Shea, Reductive and oxidative degradation of iopamidol, iodinated X-ray contrast media, by Fe(III)-oxalate under UV and visible light treatment, Water Res. 67 (2014) 144-153.

[6] S.E. Duirk, C. Lindell, C.C. Cornelison, J. Kormos, T.A. Ternes, M. Attene-Ramos, J Osiol, E.D. Wagner, M.J. Plewa, S.D. Richardson, Formation of toxic iodinated disinfection by-products from compounds used in medical imaging, Environ. Sci. Technol. 45 (2011) 6845-6854.

[7] F.M. Wendel, C.L. Eversloh, E.J. Machek, S.E. Duirk, M.J. Plewa, S.D. Richardson, T.A. Ternes, Transformation of iopamidol during chlorination, Environ. Sci. Technol. 48 (2014) 12689-12697.

[8] W. Seitz, J.Q. Jiang, W. Schulz, W.H. Weber, D. Maier, M. Maier, Formation of oxidation by-products of the iodinated X-ray contrast medium iomeprol during ozonation, Chemosphere 70 (2008) 1238-1246.

[9] J. Jeong, J. Jung, W.J. Cooper, W.H. Song, Degradation mechanisms and kinetic studies for the treatment of X-ray contrast media compounds by advanced oxidation/reduction processes, Water Res. 44 (2010) 4391-4398.

[10] B. Ning, N.J.D. Graham, P.D. Lickiss, A comparison of ultrasound-base advanced oxidation processes for the removal of X-ray contrast media Water Sci. Technol. 60 (2009) 2383-2390.

[11] Y.W. Gao, Z.Y. Zhang, S.M. Li, J. Liu, L.Y. Yao, Y.X. Li, H. Zhang, Insights into the mechanism of heterogeneous activation of persulfate with a clay/iron-based catalyst under visible LED light irradiation, Appl. Catal., B 185 (2016) 22-30.

[12] A. Rastogi, S.R. Ai-Abed, D.D. Dionysiou, Sulfate radical-based ferrousperoxymonosulfate oxidative system for PCBs degradation in aqueous and sediment systems, Appl. Catal., B 85 (2009) 171-179.

[13] J.W.L. Fordham, H.L. Williams, The persulfate-iron (II) initiator system for free radical polymerizations, J. Am. Chem. Soc. 73 (1951) 4855-4859.

[14] I.M. Kolthoff, I.K. Miller, The chemistry of persulfate. I. The kinetics and mechanism of the decomposition of the persulfate ion in aqueous medium, J. Am. Chem. Soc. 73 (1951) 3055-3059.
[15] Y.G. Adewuyi, M.A. Khan, Nitric oxide removal by combined persulfate and ferrous-EDTA reaction systems, Chem. Eng. J. 281 (2015) 575-587.

[16] D.H. Han, J.Q. Wan, Y.W. Ma, Y. Wang, M.Z. Huang, Y.M. Chen, D.Y. Li, Z.Y. Guan, Y. Li, Enhanced decolorization of Orange G in a Fe (II)-EDDS activated persulfate process by accelerating the regeneration of ferrous iron with hydroxylamine, Chem. Eng. J. 256 (2014) 316-323.

[17] X.L. Wu, X.G. Gu, S.G. Lu, M.H. Xu, X.K. Zang, Z.W. Miao, Z.F. Qiu, Q. Sui, Degradation of trichloroethylene in aqueous solution by persulfate activated with citric acid chelated ferrous ion, Chem. Eng. J. 255 (2014) 585-592.

[18] M. Sillanpaa, K. Pirkanniemi, Recent developments in chelate degradation, Environ. Technol. 22 (2001) 791-801.

[19] H.Y. Dong, C. Sans, W.T. Li, Z.M. Qiang, Promoted discoloration of methyl orange in $\mathrm{H}_{2} \mathrm{O}_{2} / \mathrm{Fe}$ (III) Fenton system: effects of gallic acid on iron cycling, Sep. Purif. Technol. 171 (2016) 144-150.

[20] C.J. Liang, C.F. Huang, N. Mohanty, R.M. Kurakalva, A rapid spectrophotometric determination of persulfate anion in ISCO, Chemosphere 73 (2008) 15401543.

[21] L. Herrera, P. Ruiz, J.C. Aguillon, A. Fehrmann, A new spectrophotometric method for the determination of ferrous iron in the presence of ferric iron, J. Chem. Technol. Biotechnol. 44 (1989) 171-181.

[22] S.P. Sun, X. Zeng, A.T. Lemley, Kinetics and mechanism of carbamazepine degradation by a modified Fenton-like reaction with ferric-nitrilotriacetate complexes, J. Hazard. Mater. 252 (2013) 155-165.

[23] E.D. Hood, N.R. Thomson, D. Grossi, G.J. Farquhar, Experimental determination of the kinetic rate law for the oxidation of perchloroethylene by potassium permanganate, Chemosphere 40 (2000) 1383-1388.

[24] C.J. Liang, C.J. Bruell, Thermally activated persulfate oxidation of trichloroethylene: experimental investigation of reaction orders, Ind. Eng. Chem. Res. 47 (2008) 2912-2918.

[25] M.Q. Wang, N. Wang, H.Q. Tang, M.J. Cao, Y.B. She, L.H. Zhu, Surface modification of nano- $\mathrm{Fe}_{3} \mathrm{O}_{4}$ with EDTA and its use in $\mathrm{H}_{2} \mathrm{O}_{2}$ activation for removing organic pollutants, Catal. Sci. Technol. 2 (2012) 187-194.

[26] N. Wang, L.H. Zhu, M. Lei, Y.B. She, M.J. Cao, H.Q. Tang, Ligand-induced drastic enhancement of catalytic activity of nano- $\mathrm{BiFeO}_{3}$ for oxidative degradation of bisphenol A, ACS Catal. 1 (2011) 1193-1202.

[27] M. Strlic, T. Radovic, J. Kolar, B. Pihlar, Anti- and prooxidative properties of gallic acid in Fenton-type systems, J. Agric. Food Chem. 50 (2002) 6313-6317.

[28] Y. Lei, H. Zhang, J.W. Wang, J. Ai, Rapid and continuous oxidation of organic contaminants with ascorbic acid and a modified ferric/persulfate system, Chem. Eng. J. 270 (2015) 73-79.

[29] D.H. Han, J.Q. Wan, Y.W. Ma, Y. Wang, Y. Li, D.Y. Li, Z.Y. Guan, New insights into the role of organic chelating agents in $\mathrm{Fe}(\mathrm{II})$ activated persulfate processes, Chem. Eng. J. 269 (2015) 425-433.

[30] Y. Li, T. Zhu, J.C. Zhao, B.Y. Xu, Interactive enhancements of ascorbic acid and iron in hydroxyl radical generation in quinone redox cycling, Environ. Sci. Technol. 46 (2012) 10302-10309.

[31] C.P. Huang, Y.H. Huang, Application of an active immobilized iron oxide with catalytic $\mathrm{H}_{2} \mathrm{O}_{2}$ for the mineralization of phenol in a batch photo-fluidized bed reactor, Appl. Catal., A 357 (2009) 135-141.

[32] N. Masomboon, C. Ratanatamskul, M.C. Lu, Chemical oxidation of 2, 6dimethylaniline in the Fenton process, Environ. Sci. Technol. 43 (2009) 86298634.

[33] L. Chen, X.Z. Peng, J.H. Liu, J.J. Li, F. Wu, Decolorization of Orange II in aqueous solution by an $\mathrm{Fe}(\mathrm{II}) /$ sulfite system: replacement of persulfate, Ind. Eng. Chem. Res. 51 (2012) 13632-13638.

[34] L. Zhou, W. Zheng, Y.F. Ji, J.F. Zhang, C. Zeng, Y. Zhang, Q. Wang, X. Yang, Ferrous-activated persulfate oxidation of arsenic (III) and diuron in aquatic system, J. Hazard. Mater. 263 (2013) 422-430.

[35] L.W. Chen, J. Ma, X.C. Li, J. Zhang, J.Y. Fang, Y.H. Guan, P.C. Xie, Strong enhancement on Fenton oxidation by addition of hydroxylamine to accelerate the ferric and ferrous iron cycles, Environ. Sci. Technol. 45 (2011) 3925-3930.

[36] P.L. Zamora, F.A. Villamena, Theoretical and experimental studies of the spin trapping of inorganic radicals by 5, 5-dimethyl-1-pyrroline $N$-oxide (DMPO). 3. Sulfur dioxide, sulfite, and sulfate radical anions, J. Phys. Chem. A 116 (2012) $7210-7218$.

[37] F.X. Tian, B. Xu, Y.L. Lin, C.Y. Hu, T.Y. Zhang, N.Y. Gao, Photodegradation kinetics of iopamidol by UV irradiation and enhanced formation of iodinated disinfection by-products in sequential oxidation processes, Water Res. 58 (2014) 198-208.

[38] Y.T. Woo, D. Lai, J.L. McLain, M.K. Manibusan, V. Dellarco, Use of mechanismbased structure-activity relationships analysis in carcinogenic potential ranking for drinking water disinfection by-products, Environ. Health Perspect. 110 (2002) 75-87.

[39] H.Z. Liu, T.A. Bruton, F.M. Doyle, D.L. Sedlak, In situ chemical oxidation of contaminated groundwater by persulfate: decomposition by $\mathrm{Fe}(\mathrm{III})$-and $\mathrm{Mn}$ (IV)-containing oxides and aquifer materials, Environ. Sci. Technol. 48 (2014) 10330-10336. 